\title{
Ecology and Economics of Oil Production
}

\section{Gareev $\mathbf{A A}^{*}$}

Niznesortymskneft Oil \& Gas Production Division, Russia

*Corresponding author: Adib Gareev, Niznesortymskneft Oil-and-Gas Production, Direktorate Surgut, Tyumtn region, 628447, Russia, Tel: 89324141618; Email: adibg@mail.ru

\section{Review Article}

Volume 5 Issue 1

Received Date: January 25, 2021

Published Date: February 12, 2021

DOI: $10.23880 /$ ppej-16000249

\section{Abstract}

Nowadays, the world is facing the depletion of developed reserves and the exploitation of fields with poor reservoir features. These factors are forcing oil producers to use low-capacity high-head electric centrifugal submersible pump units (ESP). The use of such ESP in oil production causes pump temperature to rise to about a hundred degrees centigrade. Increasing the temperature strength of the cable line used as part of the ESP reduces the number of failures in terms of the electrical component. In order to reduce the number of ESP failures due to cable line fusing, oil producers started using cable lines with operating temperatures of over $200 \mathrm{oC}$. Increasing the temperature strength of the cable line used as part of the ESP leads to a partial decrease in failures due to a reduction in the electric resistance of the "cable-motor" system. Meanwhile, failures of ESPs due to salt deposition in the pump stages started to grow. In the absence of any theoretical insight into the salt deposition phenomenon, ESP manufacturers started providing oil producers with various devices to protect pump stages from salt deposition. However, it soon became clear that these devices (containers with chemical salts) show no tangible results in terms of salt deposition elimination; hence, over the past few years, oil production enterprises have been maintaining the proper operation of ESPs by the regular dosing of chemicals to the pump suction or by hydrochloric acid treatment. Investigation of the failed ESP units has reliably ascertained the following: formation and effect of high temperature in and around the centrifugal pump; effect of the pump's high temperature on the adjacent cable line; application of cable lines with high operating temperatures leads to salt deposition in the centrifugal pump chamber; salt deposition accompanies temperature deformation of the cable line's insulation; acid treatment does not protect the ESP unit against salt deposition; acid treatment may result in the wear of a flow string; Therefore, solution of the salt deposition problem should start with an investigation of the dependence of a centrifugal pump's temperature on the oil reservoir's working parameters. The solution of many oil production problems and a reduction in oil recovery costs can only be achieved by means of ESP control automation. The described revolutionary studies of ESP operation in oil recovery will lay the foundation for a complete robotization of oil production.

Keywords: Oil production; Centrifugal pumps in oil production; Depletion of oil reserves; Operation of wells with low inflow; The occurrence of problems in the operation of centrifugal pumps; Salt deposition as a result of energy dissipation in the pump; Operation with the dissipation of energy is an inefficient method of operation; Salt deposition is an environmental disaster 


\section{Petroleum \& Petrochemical Engineering Journal}

\section{Investigation of a Centrifugal Pump's Thermal Behavior}

Mathematical description of a pump's thermodynamic condition for the purposes of assessing the pump's temperature and determining its dependency on the ESP unit's operating parameters leads to the solution of a nonlinear thermal-conductivity equation under boundary conditions of the 2 nd and 4 th kind [1-4], since in the processes taking place inside the ESP, the heat source (dissipation of mechanical energy) is nonlinear (relationship between the friction coefficient and the temperature of mating surfaces, etc.); the change in the heat-absorption capacity of the liquid-gas mixture (oil) under high pressure and with complicated chemical composition has not been studied; the "temperature-pressure" function of oil saturated with VHC is underexplored. The transfer of heat from the metal mating surfaces to the fluid and from the fluid to the metal pump housing is a complicated process (in the first place, because of the sophisticated shape of the labyrinths in the pump's working elements and the complicated dependency of the physical and chemical properties of the liquid-gas mixture); however, it is expected that this is a convection process, since other heat-transfer techniques, like mass transfer or radiant interchange, produce a minor effect; so at first approximation, this process can be ignored $[5,6]$. Due to the substantial difference between the heat conductivity of the oil-gas and the fluid, we may assume that each pump section transfers a small amount of heat to the surrounding fluid and further to the production string, i.e. that the pump stays in a kind of "thermostat." Thus, the amount of heat generated in the centrifugal pump's working elements is partly spent on heating of the fluid and the metal parts of the pump and partly transferred to the other assemblies of the ESP unit [2-4,7-14]. The temperature rise of the pump ( $\Delta \mathrm{Tw})$ may be expressed by the formula (1) as follows:

$$
\Delta T_{w}=T_{w}-T_{f}=\frac{\phi}{1-\phi} \frac{q_{0} P_{b} P_{t p} R_{2}}{2(1-B) h \Gamma_{a} P_{a t}}\left\{\frac{1}{\alpha}+\frac{\delta_{t g}}{\lambda_{g b}}\right\}
$$

where:

$T_{w}$ : temperature inside the pump housing, $T_{f}$ temperature of the liquid-gas mixture on the intake side, $R_{2}$ : radius of the pump's cylindrical housing $(0.05 \mathrm{~m}), P_{b}$ : bubble-point pressure (MPa), $\Gamma_{a}$ : reservoir gas-oil ratio $\left(\mathrm{m}^{3} / \mathrm{m}^{3}\right), h$ : pump head $(\mathrm{MPa})$ with free gas $\varphi$ in the mixture (fraction), $\delta_{t g}$ : thickness of gas bubbles on the pump surface (about 0.002-5 $\mathrm{m}), \mathrm{B}$ : water content in the production stream, in fractions (less than 0.98), $\lambda_{g b}$ : gas blanket heat conductivity on the pump's housing surface $\left(\mathrm{W} /\left(\mathrm{m}^{*} \mathrm{~K}\right)\right), \alpha$ : convection heattransfer coefficient $\left(\mathrm{W} /\left(\mathrm{m}^{2 *} \mathrm{~K}\right)\right)$ in the labyrinths of pump elements with respect to the liquid-gas mixture, $q_{0}$ : heatsource power density per one running pump $\left(\mathrm{W} / \mathrm{m}^{3}\right), P_{a t}$ : atmospheric pressure (MPa), $\mathrm{P}_{\mathrm{tp}}$ : the pressure at the inlet of the pump, (MPa).

\section{Analysis of the Obtained Mathematical Expression}

The obtained mathematical expression (1) enables us to determine the centrifugal pump's suction pressure $[1,2]$, which in turn allows for investigation of the pump's potential conditions. The phenomena of "automatic relaxation oscillation" and of "heat shock" leading to the centrifugal pump's sudden failure have been discovered.

Salt deposition in oil-production equipment is a rathercommon yet poorly-explored phenomenon. This is because of the established opinion among experts that salt deposition is mainly caused by the supersaturation of the formation fluid (water) by a particular component of dissolved substances $[6,12]$. However, both oil-production practice and the available facts of salt deposition provide evidence that the presence of dissolved salts in associated water and their condition are just a prerequisite. The sufficient condition for the formation of salt deposits in centrifugal-pump stages is high temperature, namely the boiling of associated water in the pump [8-11].

\section{Salt Deposition Issues with Respect to a Centrifugal Pump}

Fluid-boiling questions, in particular, the boiling of clean and technical water, have been well studied by science; for example, it is known that the initial boiling point of pure water depends on the condition of the heat-delivery surface, its roughness, pressure in the vessel, etc [1,5,], and depends only slightly - if at all - on certain parameters like viscosity, surface tension, and the presence of several salts dissolved in water. The boiling of water starts on a heated non-wetted surface with microscopic dimples. The boiling mechanism was considered by experiment and studied in detail by Oddo and Thomas early last century [1,2]. The scaling mechanism during the boiling of water with dissolved salts is shown in Figure 1.

The surface tension force $\mathrm{F}$ in the dimple D on the "liquid - hydrophobic surface" border promotes the generation of a low-pressure zone, which leads to the formation of a vapor bubble nucleus. The bubble growth is provided by the molecules of water supplied from the heat flow surface. The direction of heat flow from the heated surface is denoted by T. Scaling starts on the "bubble-liquid-solid" border S. 


\section{Petroleum \& Petrochemical Engineering Journal}

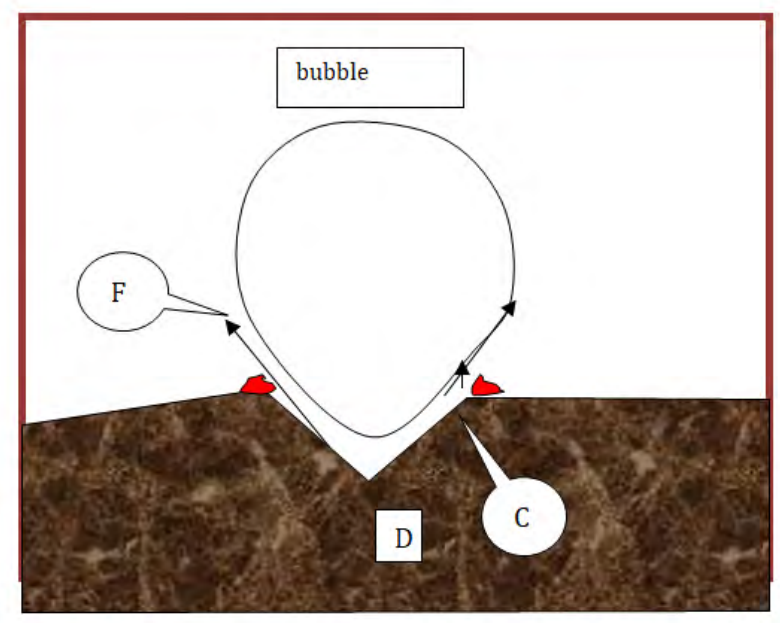

Figure 1: Bubble growth mechanism on a hydrophobic surface due to molecular repulsion forces on the "liquid - hydrophobic surface" border. C-ring-shaped scaling location, V-bubble inflation with vapor, T-heat flow direction on the "liquid-hydrophobic surface" border, S-scale, F-surface tension force, D-dimple.

By studying the bubble formation mechanism during boiling, it is possible to propose a method of boiling or salt deposition/scaling prevention: 1) the heat delivery surface must be absolutely smooth; 2) boiling of the liquid under the set temperature may be prevented by increasing the pressure above the liquid. No scaling (salt formation) takes place without boiling of the liquid. The same thing happens in a centrifugal pump - ESP operation at a temperature below the water boiling point in the recovered liquid-gas mixture prevents salt deposition.

The "water boiling point - pressure" function has the shape of curve K shown in Figure 2.

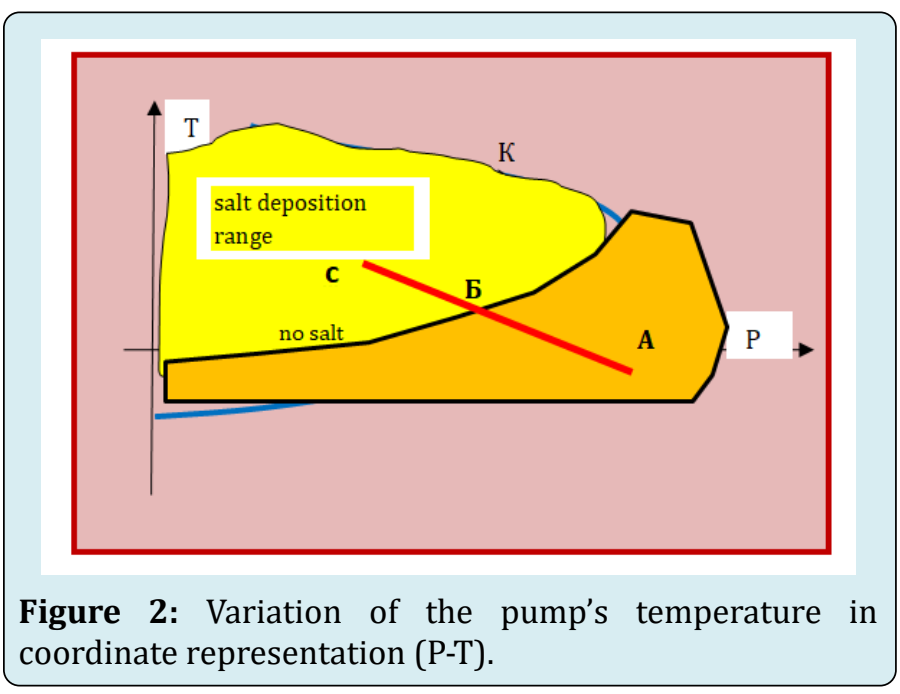

\section{Salt Deposition Dynamics}

The process of salt deposition in a centrifugal pump may be represented in temperature and pressure coordinates at the pump suction (Figure 1). Water thermal behavior vs. pressure has been studied rather extensively [1]. Depending on the salts dissolved in the water, curve $K$ has a certain "width" in the form of deviation (in either direction) from the pure water parameter. According to the research, this deviation of the water boiling point from the chemically-pure water boiling point amounts to a maximum of $3-6^{\circ} \mathrm{C}$.

When the pump's suction pressure decreases from point A to point 5 , no salt deposition is observed. Point $\bar{b}-$ the water boiling point-represents the start of salt deposition. During operation of the pump, its suction pressure will stay within the range of $5-\mathrm{C}$ and will be accompanied by salt deposition. Curve $\mathrm{K}$ represents the "water boiling point $\mathrm{T}$ pressure $\mathrm{P}$ " function.

If, during operation, the pump's suction pressure moves from $A$ to $\bar{b}$, the temperature ramp-up of both the pump and the pumped liquid-gas takes place. When the pump's temperature reaches point 5 , the gas-liquid mixture's temperature becomes equal to the water boiling point. Reverse movement from point $\mathrm{B}$ towards point $\mathrm{A}$ can be achieved by changing the centrifugal pump's capacity, e.g. by reducing the pump's shaft rotation speed with a frequency converter. Return from point $\mathrm{B}$ towards point $\mathrm{A}$ is possible by means of shutting-down the ESP unit for a certain period of time (autoreclosing mode) [15-17].

\section{Concerning the Possibility of Changing Operating Parameters}

From the above theoretical speculations it becomes clear that by changing the centrifugal pump's operating parameters one way or the other, the pump's temperature can be suppressed below the associated water boiling point. However, theoretical (and practical for that matter) studies show that there is an operating mode in which the pump's temperature rises uncontrolled and the ESP immediately breaks down. Let's call this mode "heat shock." This mode arises during pump heatup, when two concurrent and mutually-competing processes take place: on the one hand, the gas-liquid mixture's pressure boost causes dilution of the liberated gas. On the other, along with the pump's temperature rise, oil saturation pressure goes up, promoting a reversal process - gas escape from oil. Under certain operating conditions, the pump's temperature rise may lead to increasing gas escape. Meanwhile, the pump's condition surpasses its critical behavior. Heat shock behavior can be predicted if the saturation pressure change as a function of the pump's temperature is taken into account. Depending 


\section{Petroleum \& Petrochemical Engineering Journal}

on the temperature at a constant volume of associated gas, saturation pressure can be calculated according to the formula [18], provided the proportional content of methane and nitrogen is known:

$$
P_{S, v}=P_{s p}+\frac{T-T_{r t}}{9.157+\frac{701.8}{\Gamma_{g s}\left(y_{M}-0.8 y_{a}\right)}}
$$

where $P S, v$ - saturation pressure value $(\mathrm{MPa})$ at the temperature $T ; T_{r t}$-reservoir temperature value, ${ }^{\circ} \mathrm{K}$; $P s p$ - saturation pressure at reservoir temperature; $\Gamma_{g s}$ - gas saturation (gas factor) in $\mathrm{m}^{3} / t$ of the reservoir oil, characterized by the ratio of the volume (normalized to standard conditions) of dissolved gas to the mass of degassed oil; $y_{\mathrm{M}^{\prime}} y_{\mathrm{a}}$ - respective content of methane and nitrogen in the gas (in unit fractions) of reservoir oil-flash liberation under standard conditions.

Combining (1) and (2), we get:

$$
\begin{aligned}
& \Delta T_{w}=T_{w}-T_{f}=\frac{P_{s p}+C_{1} \theta^{*} \Delta x}{\frac{1}{C_{2}}-C_{1}} \\
& C_{1}=\frac{1}{9.157+\frac{701.8}{\Gamma_{g s}\left(y_{u}-0.8^{*} y_{a}\right)}}
\end{aligned}
$$

$$
C_{2}=\frac{\varphi}{1-\varphi} \frac{q_{0} R_{2} P_{s p}}{2(1-B) h \Gamma \Gamma_{a m}}\left\{\frac{1}{\alpha}+\frac{\delta_{t g}}{\lambda_{g b}}\right\}
$$

where $\theta$ - temperature gradient in the well, $\left[{ }^{\circ} \mathrm{K} / \mathrm{M}\right], \Delta x=L_{v d}$ $L_{v d E S P}, L_{v d}-$ vertical depth of the formation top, $L_{v d E S P}-$ vertical depth of the ESP unit's installation.

Thus, for pump temperature regulation according to (1), the critical parameters must be calculated by the formula (3).

\section{Oil Production Economics}

The exploitation of oil fields is performed using electric submersible centrifugal pumps.

The ESP unit capacity affecting specific energy consumption depends on the pump's operating mode. This significantly determines oil production profitability. It has been shown that by analyzing the centrifugal pump's operating mode according to (1), it is possible to achieve the highest pump efficiency and the lowest specific energy consumption in all operating modes. That's why the ESP

\begin{tabular}{|c|c|c|}
\hline Types of Operations & Existing Control Method & Automated Control Method \\
\hline Start-up and ramp-up & no & manual labor \\
\hline Mode setting & no & manual labor \\
\hline Operational process monitoring & no & manual labor \\
\hline ESP unit repair period & & increases by several times \\
\hline Repair costs & & decrease \\
\hline $\begin{array}{l}\text { Oil production losses: } \\
\text { 1. at ramp-up } \\
\text { 2. during repair }\end{array}$ & $\begin{array}{l}\text { take place } \\
\text { happen }\end{array}$ & $\begin{array}{l}\text { manual labor } \\
\text { manual labor }\end{array}$ \\
\hline $\begin{array}{l}\text { Oil production optimization across the } \\
\text { entire oilfield }\end{array}$ & $\begin{array}{c}\text { is not possible, as a great deal of manual } \\
\text { labor is required }\end{array}$ & $\begin{array}{l}\text { is easy and yields a substantial rise in } \\
\text { oil production }\end{array}$ \\
\hline
\end{tabular}
control process demands automation.

The economic benefit of ESP control automation is shown in Table 1.

Table 1: The economic benefit of ESP control automation.

\section{Oil Production Ecology}

Today, the environmental impact is huge, causing global environmental changes. Therefore, all countries are now obliged - to one degree or another - to tackle the issues associated with reducing damaging environmental impacts. A similar problem arises during the exploitation of oil fields using centrifugal pumps. Chemical compounds
- acids destroying oil wells with the further ingress of well products into the aqueous layers - are widely used in current oil production. Modern methods of oil recovery risk causing drinking water shortages for all of mankind. As was shown above, all of these environmental threats associated with oil production can be minimized by transitioning to ESP control automation $[6,12]$. 


\section{Petroleum \& Petrochemical Engineering Journal}

\section{References}

1. Alexandrov AA Grigoriev BA (1998) Thermophysical properties of water and water vapor. Moscow Enegetic Institute, Moscow, Russia, pp: 423.

2. Vargaftik NB, Fillipov LP, Tarzimanov AA, Trotsky EE (1990) Handbook of thermal conductivity of liquids and gases. Energoizdat, Moscow, Russia, pp: 352.

3. Gareev AA (2009) On the value of the thermal regime in the installations of electric centrifugal pumps. Equipment and technologies for the oil and gas complex 1: 23.

4. Gareev AA (2009) On the limit gas content at the reception of the electric center-bearing pump, Equipment and technologies for the oil and gas complex 2: 21 .

5. Reed R, Prausnitz J, Sherwood T (1982) Properties of gases and liquids. Publishing house Chemistry, Leningrad, Russia, pp: 592.

6. Gareev AA (2020) Automation the Pathway to "Green" Oil-Production Technology. Transactions on Engineering and Computer Science, Gnoscience Group.

7. Gareev AA (2010) On the gas separation coefficient at the pump reception. Oil Economy 6: 90.

8. Gareev AA, Urazakov KR (2010) The effect of the efficiency of a centrifugal pump on its thermal regime. Equipment and Technologies for the oil and Gas complex 5: 21.
9. Gareev AA (2010) On the temperature regime of an electric submersible pump. Equipment and Technologies for the oil and gas complex 6: 35 .

10. Gareev AA (2011) On the temperature regime and the phenomenon of heat shock in an electric center-bearing pump (in the order of discussion). Oil Economy 3: 122.

11. Gareev AA (2012) On the pressure value at the intake of the centrifugal pump. Oil industry 10: 128.

12. Labuntsov DA (2000) Physical bases of power engineering. Moscow. Moscow Power Engineering Institute, Russia, pp: 388.

13. Gareev AA (2013) Modern problems of operation of lowperformance electric centrifugal pumps in oil production. Bashkir State University, Monograph, Russia.

14. Gareev AA (2013) Calculation of the gas separation coefficient at the pump reception. Oil Industry 3: 82.

15. Gareev AA (2020) Centrifugal pumps in oil production (problems and solutions). Oriental print, Ufa, Rostia.

16. Gareev AA (2018) Technology of operation of electric centrifugal pumps without salt deposition. Equipment and technologies for the oil and gas complex 3: 27.

17. Gareev AA (2017) On the mechanism of salt deposition. Neftepromyslovoe delo 4: 35.

18. Gareev AA (2020) Centrifugal pumps in oil recovery (problems and solutions). 